\title{
Aging and Mitochondrial DNA
}

Review

\author{
P. Das ${ }^{1}$ and G. Guha ${ }^{2 *}$ \\ ${ }^{1}$ Department of Biological, Geological and Environmental Sciences, Cleveland State University, \\ Cleveland, Ohio, USA \\ ${ }^{2}$ Division of Biomedical Sciences, School of Bio Sciences and Technology, VIT University, \\ Vellore, Tamil Nadu, India
}

Received 21 May 2010, accepted in final revised form 21 September 2010

\begin{abstract}
According to the mitochondrial theory of aging, accrual of mutations in mitochondrial DNA (mtDNA) plays the paramount function in the cellular pathology of aging and in development of age-related degenerative ailments. Reactive oxygen species (ROS), which are byproducts of oxidative phosphorylation (OX-PHOS) in aerobic (mitochondrial) respiration, cause oxidative stress-induced damage to mtDNA. This damaged DNA, whose normal role is to encode proteins many of which are players in the electron transport chain (ETC), now codes for defective proteins. Such faulty proteins lead to a considerable impairment in the efficacy of ETC, thereby generating more ROS, which cause further damage to mtDNA in turn, leading to further defects in proteins, aggravated ETC dysfunction, and even more ROS. Hence, a 'vicious cycle' propagates that ultimately directs tissue cells towards structural and functional decline, or in other words, degeneration and aging. However, in spite of a wide acceptance of this theory, there have simultaneously been a considerable number of criticisms against it. This review is aimed at discussing the paradigm of aging and degenerative diseases in light of the mitochondrial paraphernalia, with reference to the evidences in support as well as in antagonism to the mitochondrial theory of aging.
\end{abstract}

Keywords: Aging; Degenerative diseases; mtDNA mutations; ROS; Cell death.

(C) 2011 JSR Publications. ISSN: 2070-0237 (Print); 2070-0245 (Online). All rights reserved. doi:10.3329/jsr.v3i1.5078 J. Sci. Res. 3 (1), 176-186 (2011)

\section{Introduction}

Aging is characterized by a decline with temporal dependence in the physiology of a living organism [1], involving structural and functional degeneration in cells, tissues and organs. Harman [2] suggested that mitochondria might be the biological clock in aging. Differential attenuation in oxidative phosphorylation (OX-PHOS) capacity of mitochondria occurs with aging in different tissues [3]. Mitochondria produce reactive oxygen species (ROS), such as superoxide $\left(\mathrm{O}_{2}^{-}\right)$radicals, hydrogen peroxide $\left(\mathrm{H}_{2} \mathrm{O}_{2}\right)$,

\footnotetext{
* Corresponding author: gunjan.doc@gmail.com
} 
hydroxyl radical $\left({ }^{\bullet} \mathrm{OH}\right)$, and singlet oxygen. The rate of mitochondrial ROS generation has significant positive correlation to the steady-state level of oxidative stress to mitochondrial DNA (mtDNA), and is negatively correlated with maximum longevity in higher vertebrates. Incidences of large deletions and point mutations in mtDNA occur at diverse sites all along the mtDNA; even in its main control region, which is critical for its replication. Such pathogenic mtDNA mutations have paramount role in induction of apoptosis and consequent tissue degeneration [3].

\section{Electron transport Chain (ETC), ROS and mtDNA Damage}

Human mtDNA, a circular double-stranded 16,569 bp non-histone molecule, encodes 13 polypeptides, of which seven belong to ETC complex I (NADH dehydrogenase), one to Complex III (cytochrome b), three to complex IV (cytochrome c oxidase), and two to complex V (ATP synthase). Mitochondrial genes lack introns and intergenic sequences [4]. ROS generated during aerobic respiration in live cells through OX-PHOS play a primary role in mtDNA damage [3, 5]. Levels of 8-hydroxy-2-deoxyguanosine (8-OHdG), the most copious among the oxidative products of nucleotides, are found to be 16 times higher in mtDNA than in nuclear DNA in rat liver cells [6]. Furthermore, mitochondrial 8OHdG increases up to 3-fold with age [3]. Since histones, introns and intergenic 'junk' sequences are lacking in mtDNA, any damage directly affects the protein-coding efficacy of the mitochondrial genes, thereby forming defective functional proteins. Moreover, oxidative products of DNA cause deleterious effects to diverse proteins and lipids. Secondary damage in mtDNA also occurs in continuum [3], gradually resulting in accumulation of damage in mtDNA. Such cumulative damage overwhelms the ability of biological systems to repair per se, causing an inevitable functional and structural decline, i.e., aging (or degeneration) [5]. Oxidative damage to mitochondrial protein, lipids and DNA possibly lead to cell death, thereby explaining the loss of cells observed with aging and in degenerative diseases [7].

\section{The 'Vicious Cycle'}

Oxidation-induced mtDNA mutagenesis produces a progressive deterioration throughout life in the respiratory capacity of an organism. A feedback loop, popularly called a 'vicious cycle' (Fig. 1), propagates this chronological degenerative machinery. Progressively accumulating mtDNA mutations account for a commodious deficiency in cellular OX-PHOS activity (through defective functional protein expression) leading to an enhanced ROS production which results in an increased rate of mtDNA damage, an additional production of defective proteins, and a further collapse in OX-PHOS efficiency. The 'vicious cycle' of exponentially increasing oxidative damage and dysfunction hence propagates [3]. 


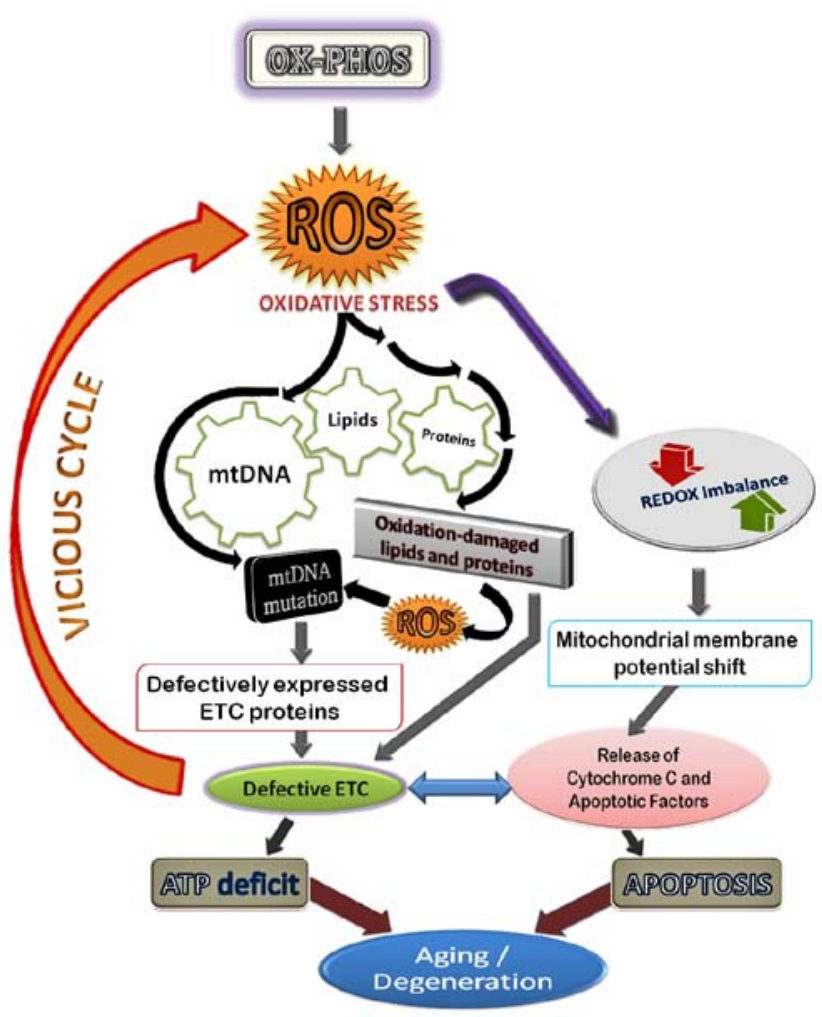

Fig. 1. Schematic representation of the mechanism of mtDNA-mutation induced degeneration and aging. OX-PHOS: oxidative phosphorylation ; ROS: reactive oxygen species.

\section{Oxidative damage in mtDNA: Deletions and Point Mutations}

Ever-increasing levels of ROS in the mitochondrial matrix lead to occurrence of large deletions and point mutations in mtDNA [3]. Lofty accumulations of large deletions in tissues are correlated with the age-dependent increase in 8-OHdG and other oxidative adducts in mtDNA. Such deletions, previously thought to occur only in individuals with neuromuscular disease [8], were related to aging by several studies involving diverse tissue systems [9, 10]. Age-dependent incidences of $5 \mathrm{~kb}$ and $6 \mathrm{~kb}$ deletions were also detected in human liver mtDNA [11, 12]. Simultaneously, high numbers of different point mutations at specific positions in mtDNA appeared only in old individuals [13]. Such deletion and mutation-harboring mtDNAs coexist in heteroplasmy with wild-type mtDNAs, although the biochemical and clinical symptoms are not manifested until their proportion reaches a certain critical value $[14,15]$. Table 1 enlists significant agingrelated mtDNA deletions and point mutations. 
Table 1. Frequently encountered mtDNA deletions and point mutations related to degenerative diseases and aging.

\begin{tabular}{lccc}
\hline \multicolumn{4}{c}{ Large Deletions in mtDNA } \\
\hline Deletions & $\begin{array}{c}\text { Nucleotide } \\
\text { positions }\end{array}$ & References \\
\hline 4977 bp & 8483 to 13459 & $\begin{array}{c}\text { Liver, muscle, brain, heart, lung, spleen, } \\
\text { testis, diaphragm, kidney, adrenal gland } \\
\text { and skin. }\end{array}$ & $11,16-21$ \\
7436 bp & 8649 to 16084 & $\begin{array}{c}\text { Heart, muscle, liver, and skin. } \\
\text { (2) }\end{array}$ & $22-24$ \\
3663 bp & 7842 to 13904 & Muscle and liver. & 12,24 \\
5827 bp & 1837 to 5446 & Muscle. & 25 \\
6335 bp & 8993 to 13786 & Muscle. & 18 \\
7635 bp & 8440 to 16074 & Muscle. & 18 \\
8041 bp & 8035 to 16075 & Muscle. & 18 \\
\hline
\end{tabular}

Point Mutations in mtDNA

\begin{tabular}{ccc}
\hline Mutation & Affected Tissues/Cells & References \\
\hline A-8334-G & Extraocular muscles. & 26 \\
A-3243-G & Extraocular muscles. & 26 \\
T-414-G & Skin fibroblasts. & 27 \\
A-189-G & Muscles. & 28 \\
T-408-G & Muscles. & 3 \\
\hline
\end{tabular}

\section{Apoptosis}

Degeneration of mtDNA plays the key role in aging-related apoptosis. The most crucial abuse that mtDNA mutations do to a cell is impairment of function so much as to lead to cell death [29]. Elevated levels of mtDNA mutations lead to mitochondrial dysfunction, while respiratory chain deficiency due to reduced mtDNA expression causes ATP deficit. Consequently, the viability of the cells is compromised, thereby causing apoptosis [30]. Mitochondrial dysfunction, induced by a variety of oxidative stresses has been shown to induce apoptosis in cultured neurons and cardiomyocytes [31-33]. TUNEL-positive staining was observed in about $75 \%$ of muscle fibers in patients carrying a high percentage ( $>40 \%$ ) of mtDNA deletions [34] and in $25-75 \%$ of muscle fibers in patients carrying high proportions ( $>70 \%$ ) of the A3243G or the A8344G mutations [3]. ROS generated due to mtDNA mutations induce phosphorylation of protein kinase $\mathrm{C} \delta(\mathrm{PKC} \delta)$ 
at Tyr-512 and Tyr-523, which in turn leads to loss of mitochondrial transmembrane potential, release of cytochrome c, and apoptosis [35].

\section{Mitochondrial Functional Contingency on Nuclear Genes}

A number of protein subunits of the OX-PHOS system are encoded by the nuclear genome [36]. It is, hence, imperative to discuss the role of nuclear gene-encoded mitochondrial proteins in context of the mitochondrial theory of aging. Complex I deficiency results in multi-system anomalies involving brain, heart, kidney and skeletal muscles [36]. The commonly encountered degenerative conditions associated with mitochondrial Complex I deficiency are Leigh syndrome [37], cardiomyopathy, fatal infantile lactic acidosis, macrocephaly with progressive leukodystrophy and encephalopathy [38]. These conditions have been associated with mutations in the following nuclear subunits of complex I: NDUFS4 (W15X, W96X and R105X), NDUFS7 (V122M), NDUFS8 (P79L, R102H), NDUFS1 (R241W, D252G, R55X, M707V) and NDUFV1 (including R59X, Y204C, C206G, E214K etc.) [36].

Complex II is the only OX-PHOS complex whose subunits are entirely encoded by nuclear genes [36]. Several mutations in these genes have been correlated to mitochondria-related pathological conditions. Mutations in SDHA gene have been proved to cause autosomal recessive Leigh syndrome [39]. Hereditary paraganglioma has been reported to be associated with mutations in the SDHC and SDHD genes [40], while familial pheochromocytoma is linked to mutations in the SDHB and SDHD genes [40].

No mutations have been identified in nuclear genes which could be correlated with complex III deficient conditions [36]. Similarly, complex IV deficiency too could not be related to any nuclear gene mutations [36]. However, mutations have been identified in certain genes which are required for biogenesis of cytochrome c oxidase complex. These genes are: SURF-1 [41], SCO2 [42] and SCO1 [43]. Complex V, again, has not been linked to any deficient conditions associated with nuclear gene mutations [36].

\section{Prophylactic Strategies}

\subsection{Caloric restriction}

The concept of constraint in the dietary intake, called caloric restriction (CR), is based on the idea that CR can extend life-span and promote the long-term survival of irreplaceable cells [44]. The strategy has been proved to be effective grossly in mammals [45]. Even in yeast, CR has been shown to delay aging [46].CR retards oxidative stress-related damage and aging in mammals by lowering mitochondrial ROS-induced oxidative stress [47], and was found to increase maximum life span [48]. However, age-related alterations in energy metabolism are tissue specific, and that CR is unable to attenuate these effects in all types of tissues with equal competence [49]. For example, in mitochondria of liver, heart, brain and kidney, there were no significant effects of CR [50]. Nevertheless, there is evidence 
that CR acts by decreasing oxidative stress and damage as well as by increasing antioxidant defenses and repair systems [51].

\subsection{Antioxidant supplementation}

Antioxidants directly quench ROS or chelate the catalytic metal ions [52], thereby preventing damage to cellular macromolecules. For example, $\alpha$-tocopherol has been established as an effective mitochondrial antioxidant [53]. Supplementation of vitamin E mitigated the neurological insufficiencies coupled with aging [54]. Acetylcarnitine and lipoic acid $[55,56]$ demonstrate prevention of the age-associated oxidative damage in mitochondria. Low molecular weight antioxidants, such as 2-mercaptoethylamine [57], ethoxiquin [58] and 2-ethyl-6-methyl-3-hydroxy-pyridine [59], were able to produce a 13$29 \%$ increase in median life span. Hence, targeting mitochondrial ROS with various antioxidants might protect mtDNA from oxidative damage. Natural antioxidants in floral resources hold great untapped potential in this direction.

\subsection{Overexpression of mitochondrial antioxidant enzymes}

Transgenic mice with overexpressed human catalase in heart mitochondria have been reported to attain increased life span [60]. Catalase converts $\mathrm{H}_{2} \mathrm{O}_{2}$ into water and oxygen preventing it from becoming a highly reactive hydroxyl radical. This reasonable increase in life span resulting from the upregulation of a single gene implies that the upregulation of a few more similar genes might result in striking improvement in life span [61]. The overexpression of $\mathrm{Cu}, \mathrm{Zn}-\mathrm{SOD}$ and catalase in transgenic Drosophila melanogaster also extended life span [62]. Thus, decreased mitochondrial $\mathrm{O}_{2}^{-}$and $\mathrm{H}_{2} \mathrm{O}_{2}$ steady-state concentrations due to overexpression of mitochondrial antioxidant enzymes seem to induce an extended survival.

\subsection{MitoSENS}

'Strategies for engineered negligible senescence' (SENS) has been a topic of extreme debates since it was proposed by the British biogerontologist Aubrey de Grey in 1999 [63]. Its mitochondrial facet, the MitoSENS, involves relocating damage-prone mtDNA genes completely into nuclear genome, which has advanced protection against ROSinduced damage and functional DNA repair mechanisms [63]. This far-fetched goal, albeit yet to be proven, might hold promise in the long run of geriatric research.

\section{Challenges to the Mitochondrial Theory of Aging}

In spite of the general acceptance of the theory, there have been many criticisms against it. Nohl et al. [64] have argued that it is impractical to assume that mitochondria are the main source of ROS in all cell types and under all physiological conditions. Others have 
highlighted the fact that $\mathrm{O}_{2}^{-}$production by mitochondria is self-limiting through inactivation of mitochondrial aconitase $[65,66]$. Some workers have challenged the idea that proximity of mtDNA to the ETC makes it the paramount target for oxidative damage [67-69]. Protein components, such as mitochondrial transcription factor A, have been hypothesized to provide protection to mtDNA, similar to that given by histone proteins to the nuclear DNA [70, 71]. Experimental evidence has also been put forward [72] that contradicts the theory in that mitochondrial point mutations do not limit the natural lifespan of mice. However, even in view of such challenges to the mitochondrial theory of aging, the fact remains that certain mtDNA polymorphisms have been associated with longevity. For example, in French centenarians, an augmented number of G-9055-A transition has been reported [73]. Again, certain mtDNA haplogroups with specific polymorphic loci have been found to be related with long life spans. mtDNA haplogroups J (in Italian centenarians) [74], D4a, D4b2b and D5 (in Japanese centenarians) [75, 76] have been reported to be associated with longevity. Hence, there are evidences both in favor of and antagonism to the mitochondrial theory of aging, which remains to be elucidated holistically.

\section{Conclusion}

Aging is a multifaceted process in which mtDNA plays a colossally prime role. In this review, we attempted to present the contemporary understanding of the mitochondrial theory of aging, its diverse facets, as well as the criticisms against it. Evidently, further research seems inevitable to fully elucidate the role of oxidative damage to mtDNA in aging, and to develop effective clinical medicines to inhibit age-related degeneration. The coming years might find the formulation of an 'elixir of life' which would hinder aging and extend longevity in accordance to the mitochondrial theory of aging.

\section{References}

1. B. S. Mandavilli, J. H. Santos, and B. Van Houten, Mutat. Res. 509, 127 (2002). doi:10.1016/S0027-5107(02)00220-8

2. D. Harman, J. Am. Geriatr. Soc. 20, 145 (1972).

3. A. Chomyn, and G. Attardi, Biochem. Biophys. Res. Commun. 304, 519 (2003). doi:10.1016/S0006-291X(03)00625-9

4. S. Anderson, A. T. Bankier, and B. G. Barrell, Nature 290, 457 (1981). doi:10.1038/290457a0

5. M. F. Alexeyev, S. P. Ledoux, and G. L. Wilson, Clin. Sci. 107, 355 (2004). doi:10.1042/CS20040148

6. C. Richter, J. W. Park, and B. N. Ames, Proc. Natl. Acad. Sci. USA 85, 6465 (1988). doi:10.1073/pnas.85.17.6465

7. S. Raha, and B. H. Robinson, Trends Biochem. Sci. 25, 502 (2000). doi:10.1016/S0968-0004(00)01674-1

8. N. Arnheim, and G. Cortopassi, Mutat. Res. 275, 157 (1992).

9. M. Hayakawa, K. Torii, S. Sugiyama, M. Tanaka, and T. Ozawa, Biochem. Biophys. Res. Commun. 179, 1023 (1991). doi:10.1016/0006-291X(91)91921-X

10. M. Hayakawa, S. Sugiyama, K. Hattori, M. Takasawa, T. Ozawa, Mol. Cell Biochem. 119, 95 (1993). doi:10.1007/BF00926859 
11. T. C. Yen, J. H. Su, K. L. King, and Y. H. Wei, Biochem. Biophys. Res. Commun. 178, 124 (1991). doi:10.1016/0006-291X(91)91788-E

12. T. C. Yen, C. Y. Pang, R. H. Hsieh, C. H. Su, K. L. King, and Y. H. Wei, Biochem. Int. 26, 457 (1992).

13. Y. Michikawa, F. Mazzucchelli, N. Bresolin, G. Scarlato, and G. Attardi, Science 286, 774 (1999). doi:10.1126/science.286.5440.774

14. J. I. Hayashi, S. Ohta, A. Kikuchi, M. Takemitsu, Y. I. Goto, and I. Nonaka, Proc. Natl. Acad. Sci. USA 88, 10614 (1991). doi:10.1073/pnas.88.23.10614

15. G. Fayet, M. Jansson, D. Sternberg, A. R. Moslemi, P. Blondy, A. Lombes, M. Fardeaua, and A. Oldfors, Neuromuscul. Disord. 12, 484 (2002). doi:10.1016/S0960-8966(01)00332-7

16. G. A. Cortopassi, and N. Arnheim, Nucleic Acids Res. 18, 6927 (1990). doi:10.1093/nar/18.23.6927

17. K. Torii, S. Sugiyama, M. Tanaka, K. Takagi, Y. Hanaki, K. Iida, M. Matsuyama, N. Hirabayashi, Y. Uno, and T. Ozawa, Am. J. Respir. Cell Mol. Biol. 6, 543 (1992).

18. C. Zhang, A. Baumer, R. J. Maxwell, A. W. Linnane, and P. Nagley, FEBS Lett. 297, 34 (1992). doi:10.1016/0014-5793(92)80321-7

19. H. C. Lee, C. Y. Pang, H. S. Hsu, and Y. H. Wei, Biochim. Biophys. Acta 1226, 37 (1994).

20. J. H. Yang, H. C. Lee, K. J. Lin, Y.H. Wei, Arch. Dermatol. Res. 286, 386 (1994). doi:10.1007/BF00371798

21. H. J. Fahn, L. S. Wang, R. H. Hsieh, S. C. Chang, S. H. Kao, M. H. Huang, Y. H. Wei, Am. J. Respir. Crit. Care Med. 154, 1141 (1996).

22. K. Hattori, M. Tanaka, S. Sugiyama, T. Obayashi, T. Ito, T. Satake, Y. Hanaki, J. Asai, M. Nagano, and T. Ozawa, Am. Heart J. 121, 1735 (1991). doi:10.1016/0002-8703(91)90020-I

23. J. H. Yang, H. C. Lee, and Y. H. Wei, Arch. Dermatol. Res. 287, 641 (1995). doi:10.1007/BF00371736

24. R. H. Hsieh, J. H. Hou, H. S. Hsu, and Y. H. Wei, Biochem. Mol. Biol. Int. 32, 1009 (1994).

25. M. Katayama, M. Tanaka, H. Yamamoto, T. Ohbayashi, Y. Nimura, and T. Ozawa, Biochem. Int. 25, 47 (1991).

26. B. Kadenbach, C. Münscher, V. Frank, J. Müller-Höcker, and J. Napiwotzki, Mutat. Res. 338, 161 (1995).

27. R. Del Bo, G. P. Comi, M. P. Perini, S. Strazzer, N. Bresolin, and G. Scarlato, Ann. Neurol. 49, 137 (2001). doi:10.1002/1531-8249(200101)49:1<137::AID-ANA26>3.0.CO;2-I

28. C. Thèves, C. Keyser-Tracqui, E. Crubézy, J. P. Salles, B. Ludes, and N. Telmon, J. Forensic Sci. 51, 865 (2006). doi:10.1111/j.1556-4029.2006.00163.x

29. K. J. Krishnan, L. C. Greaves, A. K. Reeve, and D. Turnbull, Nucleic Acids Res. 35, 7399 (2007). doi:10.1093/nar/gkm635

30. J. Wang, J. P. Silva, C. M. Gustafsson, P. Rustin, and N. G. Larsson, Proc. Natl. Acad. Sci. USA 98, 4038 (2001). doi:10.1073/pnas.061038798

31. K. R. Hoyt, A. J. Gallagher, T. G. Hastings, and I. J. Reynolds, Neurochem. Res. 22, 333 (1997). doi:10.1023/A:1022403224901

32. Y. M. Jang, S. Kendaiah, B. Drew, T. Phillips, C. Selman, D. Julian, and C. Leeuwenburgh, FEBS Lett. 577, 483 (2004). doi:10.1016/j.febslet.2004.10.053

33. J. N. Keller, M. S. Kindy, F. W. Holtsberg, D. K. St Clair, H. C. Yen, A. Germeyer, S. M. Steiner, A. J. Bruce-Keller, J. B. Hutchins, and M. P. Mattson, J. Neurosci. 18, 687 (1998).

34. M. Mirabella, S. Di Giovanni, G. Silvestri, P. Tonali, and S. Servidei, Brain 123, 93 (2000). doi:10.1093/brain/123.1.93

35. P. K. Majumder, N. C. Mishra, X. Sun, A. Bharti, S. Kharbanda, S. Saxena, and D. Kufe, Cell Growth Differ. 12, 465 (2001).

36. F. M. Santorelli, and A. Tessa, Orphanet Encyclopedia, 2004

37. B. H. Robinson, Biochim. Biophys. Acta 1364, 271 (1998). doi:10.1016/S0005-2728(98)00033-4

38. J. L. C. M. Loeffen, J. A. M. Smeitink, J. M. F. Trijbels, A. J. M. Janssen, R. H. Triepels, R. C. Sengers, and L. P. van den Heuvel, Hum. Mutat. 15, 123 (2000). 
doi:10.1002/(SICI)1098-1004(200002)15:2<123::AID-HUMU1>3.0.CO;2-P

39. B. Parfait, D. Chretien, A. Rötig, C. Marsac, A. Munnich, and P. Rustin, Hum. Genet. 106, 236 (2000). doi:10.1007/s004390051033

40. S. Niemann, and U. Müller, Nat. Genet. 26, 268 (2000). doi:10.1038/81551

41. M. O. Péquignot, R. Dey, M. Zeviani, T. Tiranti, C. Godinot, A. Poyau, C. Sue, S. Di Mauro, M. Abitbol, and C. Marsac, Hum. Mutat. 17, 374 (2001). doi:10.1002/humu.1112

42. L. C. Papadopoulou, C. M. Sue, M. M. Davidson, K. Tanji, I. Nishino, J. E. Sadlock, S. Krishna, W. Walker, J. Selby, D. M. Glerum, R. V. Coster, G. Lyon, E. Scalais, R. Lebel, P. Kaplan, S. Shanske, D. C. De Vivo, E. Bonilla, M. Hirano, S. DiMauro, and E. A. Schon, Nat. Genet. 23, 333 (1999). doi:10.1038/15513

43. I. Valnot, S. Osmond, N. Gigarel, B. Mehaye, J. Amiel, V. Cormier-Daire, A. Munnich, J. P. Bonnefont, P. Rustin, and A. Rötig A, Am. J. Hum. Genet. 67, 1104 (2000).

44. H. Y. Cohen, C. Miller, K. J. Bitterman, N. R. Wall, B. Hekking, B. Kessler, K. T. Howitz, M. Gorospe, R. de Cabo, and D. A. Sinclair, Science 305, 390 (2004). doi:10.1126/science.1099196

45. R. Weindruch, Toxicol. Pathol. 24, 742 (1996). doi:10.1177/019262339602400618

46. A. Navarro, and A. Boveris, Am. J. Physiol. Cell Physiol. 292, 670 (2007). doi:10.1152/ajpcell.00213.2006

47. C. K. Lee, R. G. Klopp, R. Weindruch, T. A. Prolla, Science 285, 1390 (1999). doi:10.1126/science.285.5432.1390

48. P. Caro, J. Gómez, M. López-Torres, I. Sánchez, A. Naudi, M. Portero-Otín, R. Pamplona, and G. Barja, Rejuvenation Res. 11, 621 (2008). doi:10.1089/rej.2008.0704

49. B. Drew, S. Phaneuf, A. Dirks, C. Selman, R. Gredilla, A. Lezza, G. Barja, and C. Leeuwenburgh, Am. J. Physiol. Regul. Integr. Comp. Physiol. 284, R474 (2003).

50. A. J. Lambert, B. Wang, J. Yardley, J. Edwards, and B. J. Merry, Exp. Gerontol. 39, 289 (2004). doi:10.1016/j.exger.2003.12.009

51. G. Rao, E. Xia, M. J. Nadakavukaren, and A. Richardson, J. Nutr. 120, 602 (1990).

52. J. Robak, and E. Marcinkiewicz, Pol. J. Pharmacol. 47, 89 (1995).

53. M. W. Farris, C. B. Chan, M. Patel, B. Van Houten, S. Orrenius, Mol. Interv. 5, 94 (2005). doi:10.1124/mi.5.2.7

54. A. Navarro, C. Gómez, M. J. Sánchez-Pino, H. González, M. J. Bández, A. D. Boveris, and A. Boveris, Am. J. Physiol. Regul. Integr. Comp. Physiol. 289, R1392 (2005). doi:10.1152/ajpregu.00834.2004

55. T. M. Hagen, R. T. Ingersoll, C. M. Wehr, J. Lykkesfeldt, V. Vinarsky, J. C. Bartholomew, M. H. Song, and B. N. Ames, Proc. Natl. Acad. Sci. USA 95, 9562 (1998). doi:10.1073/pnas.95.16.9562

56. J. Liu, D. W. Killilea, and B. N. Ames, Proc. Natl. Acad. Sci. USA 99, 1876 (2002). doi:10.1073/pnas.261709098

57. D. Harman, Ann. NY Acad. Sci. 1067, 10 (2006). doi:10.1196/annals.1354.003

58. A. Comfort, Nature 230, 432 (1971). doi:10.1038/230432a0

59. N. M. Emanuel, Q. Rev. Biophys. 9, 283 (1976). doi:10.1017/S0033583500002420

60. C. E. Cooper, N. B. Vollaard, T Choueiri, and M. T. Wilson, Biochem. Soc. Trans. 30, 280 (2002). doi:10.1042/BST0300280

61. R. G. Cutler, Rejuvenation Res. 8, 138 (2005). doi:10.1089/rej.2005.8.138

62. W. C. Orr, and R. S. Sohal, Science 263, 1128 (1994). doi:10.1126/science.8108730

63. A. de Grey, Rejuvenation Res. 7, 171 (2004). doi:10.1089/rej.2004.7.171

64. H. Nohl, L. Gille, and K. Staniek, Biochem. Pharmacol. 69, 719 (2005). doi:10.1016/j.bcp.2004.12.002

65. P. R. Gardner, Biosci. Rep. 17, 33 (1997). doi:10.1023/A:1027383100936

66. P. R. Gardner, and I. Fridovich, J. Biol. Chem. 266, 19328 (1991).

67. R. M. Anson, S. Senturker, M. Dizdaroglu, and V. A. Bohr, Free Radic. Biol. Med. 27, 456 (1999). doi:10.1016/S0891-5849(99)00091-X

68. R. M. Anson, E. Hudson, and V. A. Bohr, FASEB J. 14, 355 (2000). 
69. K. S. Lim, K. Jeyaseelan, M. Whiteman, A. Jenner, and B. Halliwell, Ann. NY Acad. Sci. 1042, 210 (2005). doi:10.1196/annals.1338.023

70. N. A. Guliaeva, E. A. Kuznetsova, and A. I. Gaziev, Biofizika 51, 692 (2006).

71. T. I. Alam, T. Kanki, T. Muta, K. Ukaji, Y. Abe, H. Nakayama, K. Takio, N. Hamasaki, and D. Kang, Nucleic Acids Res. 31, 1640 (2003). doi:10.1093/nar/gkg251

72. M. Vermulst, J. H. Bielas, G. C. Kujoth, W. C. Ladiges, P. S. Rabinovitch, T. A. Prolla, and L. A. Loeb, Nat Genet. 39 (4), 445 (2007). doi:10.1038/ng1988

73. R. Ivanova, V. Lepage, D. Charron, and F. Schachter, Gerontology 44, 349 (1998). doi:10.1159/000022041

74. G. De Benedictis, G. Rose, G. Carrieri, M. De Luca, E. Falcone, G. Passarino, M. Bonafe, D. Monti, G. Baggio, S. Bertolini, D. Mari, R. Mattace, and C. Franceschi, FASEB J. 13, 1532 (1999).

75. E. Bilal, R. Rabadan, G. Alexe, N. Fuku, H. Ueno, Y. Nishigaki, Y. Fujita, M. Ito, Y. Arai, N. Hirose, A. Ruckenstein, G. Bhanot, and M. Tanaka, PLoS ONE 3, e2421 (2008). doi:10.1371/journal.pone.0002421

76. G. Alexe, N. Fuku, E. Bilal, H. Ueno, Y. Nishigaki, Y. Fujita, M. Ito, Y. Arai, N. Hirose, G. Bhanot, and M. Tanaka, Hum. Genet. 121, 347 (2007). doi:10.1007/s00439-007-0330-6 